\title{
Research on Current Cyber Bullying for Students as College Learning Disabilities
}

\author{
Zhu Jiaming ${ }^{1, \text { a }}$ Wu Pengju ${ }^{2, b} *$ \\ ${ }^{1}$ Chongqing University of Education Chongqing China \\ ${ }^{2}$ Chongqing Sanxia Institute Wanzhou Chongqing China \\ a15123991642@139.com \\ $b^{*} 15837837801 @ 139 . c o m$
}

\begin{abstract}
986 students in domestic universities have been investigated in the research for their cyber bullying experience. All participants have completed five online questionnaires about cyber bullying, social support, autognosis, happiness and body perception in the process. Results show that the proportion of students with learning disabilities is higher to be the cyber victims compared with the students without learning disabilities; the cyber victims with learning disabilities form the moderately significant correlation among the student group regarding social support, autognosis, happiness and gender; the students with learning disabilities have relatively lower autognosis and happiness, and male students have higher body perception than female students; and the gender difference between the students with learning disabilities reveals that the female students with or without learning disabilities are easier to be the cyber victims, but they have higher social support as well.
\end{abstract}

Keywords: Cyber bullying; Learning disabilities; Current situation

\section{FOREWORD}

With the Internet and mobile interaction, particularly fast growth of social media, the communication modes of people have been changed dramatically, and the communication in cyberspace has become an integral part of daily life. Although there are many benefits from social networking, the cyber bullying emerges at the proper time. The survey results for college students indicate that the college students with higher education participating in the cyber bullying have accounted for $17 \%-35 \%^{[1]}$. The cyber bullying not only brings discomfort, but also causes lower self-esteem and depression, or loss of confidence in life, and even suicide. Among them, the students with learning disabilities have higher risk in social interaction, emotion, study and other aspects compared with the students without learning disabilities ${ }^{[2]}$. Particularly, their frustration and unhappiness encountered in the real social interaction will be reflected in the network in other form. Therefore, the research on the current on-line bullying to the students with learning disabilities and the proposal of corresponding solutions have theoretical and practical significance for assisting the students with learning disabilities in better study and living.

\section{STATUS SURVEY}

The cyber bullying, also called online bullying, refers to the malicious, repetitive and hostile hurtful behaviors for individuals or groups in the Internet by people to hurt others $^{[3][4]}$. With the prevalence of social networking, the "cyber bullying" began to evolve into a global wave and became a more and more serious social problem. Although the traditional bullying and cyber bullying have similar aggressive feature, they are different as well: the cyber bullying is able to involve a wider range of target people at a faster speed, beyond the time, and the boundaries of physical and personal space ${ }^{[5]}$.

The learning disorder is ubiquitous in learning activities. Taking the learning activities of college students as an example, most of college students have insufficient learning motivation, attention-deficit disorder, poor selfcontrol, poor learning methods, strong learning anxiety and other learning disabilities, which have directly influenced their academic progress, physical and psychological health and personality development ${ }^{[6]}$. Researches show that the students with learning disorder have the risks of lower acceptability by companions, depression, anxiety and loneliness in establishing and maintaining mutual interpersonal relationship with the peers and adults compared with the students without learning disorder.

\section{RESEARCH OBJECT AND RESEARCH PROCESS}

\subsection{Research object}

2,100 college students are selected randomly and sent with emails and online questionnaires: the purposes of this research has been explained in an short email, and the participants should report any learning disabilities diagnosed in the online questionnaire in which the anonymity has been particularly declared for participants. 1,126 replies have been received after four weeks $(53.61 \%)$ In this sample, we have removed the 167 questionnaires 
with logical error and without response, and 23 questionnaires showing mental disease and disability. The final sample includes 936 completed questionnaires.

936 participants come from 73 colleges in the country, including 738 students without any learning disabilities (78.8\%) and 198 students deemed to have the learning disabilities $(21.15 \%)$. All students deemed to have the learning disabilities have been confirmed in their college medical centers (registered in the school infirmary). Most of participants are studying the undergraduate courses $(88.1 \%)$, and some of them are studying in the academy $(11.2 \%)$. A small number of participants have not clearly stated their main university or college $(0.5 \%)$. Their ages are respectively $($ Mage $=19.4$, S.D. $=3.3)$, and the gender distribution is $(63.6 \%$ of female). In the academic disciplines, $43.4 \%$ of students are majored in the humanities and social sciences, with $30.8 \%$ in natural science, $14.1 \%$ in science of thinking, $10.2 \%$ in mathematics and philosophy and others in the interdisciplinary research (Table 1). We have found out that the students with and without learning disabilities have no significant difference in age and scores, but the students with learning disabilities complete less semesters $(\mathrm{P}>.05)$ compared with hose without learning disabilities. In the research, we regard all students with learning disabilities as a group to consider.

Table 1 Statistics for Basic Information of Students

\begin{tabular}{|c|c|c|c|c|c|}
\hline \multirow[t]{2}{*}{ Variable } & \multirow{2}{*}{$\begin{array}{l}\begin{array}{l}\text { Students } \\
(\mathrm{n}=198)\end{array} \\
\mathrm{n}\end{array}$} & \multirow{2}{*}{$\begin{array}{cc}\text { learning } & \text { disabilities } \\
\%\end{array}$} & \multicolumn{3}{|c|}{$\begin{array}{l}\text { Students without learning disabilities } \\
(\mathrm{n}=738)\end{array}$} \\
\hline & & & $\mathbf{n}$ & & $\%$ \\
\hline \multicolumn{6}{|l|}{$\begin{array}{l}\text { Research } \\
\text { field }\end{array}$} \\
\hline $\begin{array}{l}\text { Social } \\
\text { sciences }\end{array}$ & 86 & 43.4 & 311 & \multicolumn{2}{|c|}{42.1} \\
\hline $\begin{array}{l}\text { Natural } \\
\text { science }\end{array}$ & 61 & 30.8 & 244 & \multicolumn{2}{|c|}{33} \\
\hline $\begin{array}{l}\text { Science of } \\
\text { thinking }\end{array}$ & 28 & 14.1 & 89 & \multicolumn{2}{|c|}{12} \\
\hline Mathematics & 12 & 6.1 & 58 & \multicolumn{2}{|c|}{7.8} \\
\hline Philosophy & 8 & 4.1 & 26 & \multicolumn{2}{|c|}{3.5} \\
\hline Unspecified & 3 & 1.5 & 10 & \multicolumn{2}{|c|}{1.6} \\
\hline \multicolumn{6}{|l|}{ Gender } \\
\hline$\overline{\text { Male }}$ & 72 & 36.4 & 206 & \multicolumn{2}{|c|}{27.9} \\
\hline \multirow[t]{2}{*}{ Female } & 126 & 63.6 & 532 & \multicolumn{2}{|c|}{72.1} \\
\hline & M & SD & M & \multicolumn{2}{|c|}{ SD t $(1,1050)$} \\
\hline Age & 19.7 & $\mathbf{3 . 2 3}$ & 18.9 & 3.43 & 0.62 \\
\hline Score & 79.3 & 7.4 & 79.7 & 8.0 & 0.66 \\
\hline $\begin{array}{l}\text { Semester } \\
\text { completed }\end{array}$ & 3.16 & 3.21 & 3.81 & 3.43 & $2.23 *$ \\
\hline
\end{tabular}

\subsection{Research process}

We have included the age, gender, diagnosis to learning disabilities, research fields and other features in the research, and conducted relevant surveys about five aspects on this account 1. Questionnaire for students with cyber bullying. Two general questions about cyber bullying experience are included: Have you been the victim of cyber bullying in the past year? Have you ever participated in cyber bullying as an offender in the past year? 2 . Questionnaire for multidimensional scaling of perceiving the social support. 12 items are included in the questionnaire, describing the opinions of participants for the usability of social support from families, friends or other close and important individuals at present ${ }^{[7]}$. 3. Scale for self-efficacy with 13 questions. The opinions of students for society and emotional autognosis have been evaluated, and the answering questionnaire of 1-5 scores has been given. Higher score reflects the higher degree of autognosis $^{[8]}$. 4. Scale for subjective happiness. This scale includes five items, aiming at measuring the global cognitive judgment of a person for life satisfaction. 5. Scale of body perception. The scale of body perception is obtained from UWE Appearance Research Center in Bristol, Britain ${ }^{[9]}$

\section{DATA ANALYSIS}

We use the statistical package for social sciences (SPSS22.0) for the current research data analysis. First, we have used Cronbach's alpha to measure the reliability of research, and then checked the gender distribution of students with and without learning disabilities. In order to 
calculate the percentages of students with or without learning disabilities reporting the cyber bullying, we regard the cyber bullying items as a classified variable, and calculate the positive or negative answers of the cyber victim. For the further inspection of cyber bullying items, $0-4$ is regarded as the continuous variable for calculation. We have used the Pearson correlation to inspect the cyber bullying, social support, autognosis, happiness, body perception and relationship between genders of the students with or without learning disabilities. Besides, we have used the variance analysis (ANOVAs) to compare the answers of the students with or without learning disabilities for cyber victims or not, and their perceived social support, autognosis, happiness and body perception.

In order to survey the number and proportion of students experiencing the online bullying, we have only calculated the positive answer of the participants being bullied online (frequently or every day almost). We have found that there is significant difference between the students with and without learning disabilities in disclosing the cyber victim. 58 students with learning disabilities (29.29\%) have reported that they are cyber victims, and 161 students without learning disabilities have reported the same $(21.81 \%), \mathrm{F}(1,1039)=4.2, \mathrm{p}=.040$.

Generally, as shown in Figure 1, the students with learning disabilities look like the cyber victims as reported in the Internet often, and a higher percentage of them have received embarrassed text, pictures and videos released maliciously (30.5\% VS $20.4 \%)$, insulting nicknames $(23.6 \%$ VS $14.3 \%$ ), anonymous speech insult (22.6\% VS 20.1\%) and mock or reviling (13.3\% VS $12.6 \%)$.

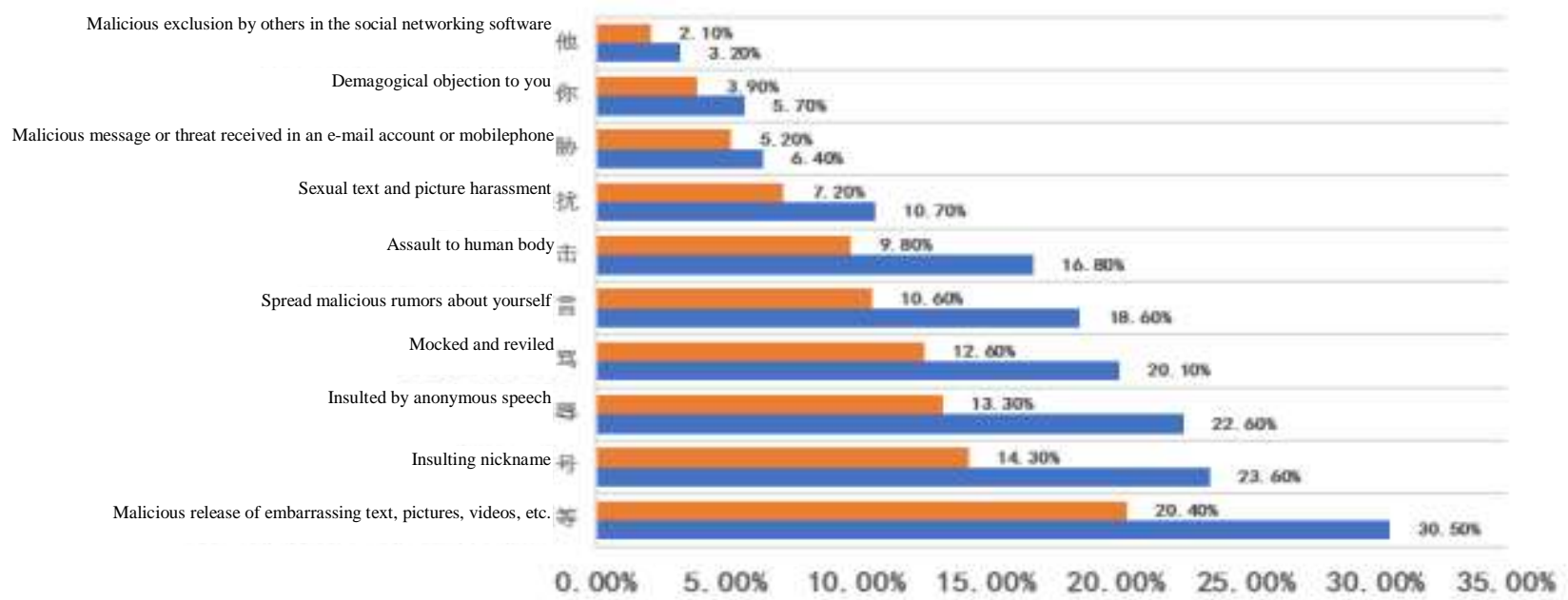

Students without learning disabilities $(\mathrm{n}=738))$ Students with learning disabilities $(\mathrm{n}=198)$

Figure 1 Classification for Cyber Bullying of Students

Besides, we have conducted the Pearson correlation analysis to inspect the cyber bullying, social emotion measurement (social support, autognosis, happiness and body perception), disability of students (having learning disabilities or not) and relationship between genders. Table
2 shows the moderately significant negative correlation among cyber bullying and social support, autognosis, happiness and gender, and the cyber bullying has positive correlation with the learning disabilities.

Table 2 Cyber Bullying, Social Support, Autognosis, Happiness, Body Perception, Disability Status and Correlation between Genders

\begin{tabular}{|c|c|c|c|c|c|c|}
\hline Variable & 1 & 2 & 3 & 4 & 5 & 6 \\
\hline 1. Cyber bullying & 1.00 & & & & & \\
\hline 2. Social support & $-.21 * *$ & 1.00 & & & & \\
\hline 3. Autognosis & $-.15^{* *}$ & $.54 * *$ & 1.00 & & & \\
\hline 4. Happiness & $-.16 * *$ & $.51 * *$ & $.62 * *$ & 1.00 & & \\
\hline 5. Body perception & -.03 & $-.18 * *$ & $-.23 * *$ & $-.18 * *$ & 1.00 & \\
\hline 6. Disability status a & $.15^{* *}$ & -.02 & $-.19 * *$ & $-.18 * *$ & .04 & 1.00 \\
\hline 7. Gender b & $-.09 *$ & $-.13 * *$ & .01 & -.01 & $.17 * *$ & .04 \\
\hline
\end{tabular}

Note: Disability status a: $0=$ non-LD, $1=\mathrm{LD}$; gender b: $0=$ female, $1=$ male.

$* p<0.05$

$* * p<0.01$ 
In order to inspect, study and measure the difference between the related student group (the students with or without learning disabilities) and gender, we have conducted the multivariate analysis of variance, including the following dependent variables: measurement of social support, autognosis, happiness and body perception. The result shows the disabled state $\mathrm{F}(5,1041)=3.08, \mathrm{p}<.01$, partially $\mathrm{Eta}^{2}=.016$, gender $\mathrm{F}(5,1041)=7.96, \mathrm{p}<.001$, and partially $\mathrm{Eta}^{2}=.041$. The difference is of statistical significance. We have found no obvious interaction between the student group (the students with or without learning disabilities) and gender.

Table 3 Average Value and Score Measured Between Students with and without Learning Disabilities and Between Genders

\begin{tabular}{|c|c|c|c|c|c|c|c|c|c|c|c|c|}
\hline \multirow[t]{2}{*}{ Variable } & \multicolumn{2}{|c|}{$\begin{array}{l}\text { Students } \\
\text { learning } \\
\text { disabilities } \\
\end{array}$} & \multicolumn{2}{|c|}{$\begin{array}{l}\text { th Students } \\
\text { without learning } \\
\text { disabilities } \\
\end{array}$} & \multirow{2}{*}{$\mathrm{F}(1.1039)$} & \multirow[b]{2}{*}{$\begin{array}{l}\text { Partial } \\
\text { Eta } \\
\end{array}$} & \multicolumn{2}{|l|}{ Male } & \multicolumn{2}{|c|}{ Female } & \multirow[b]{2}{*}{$\mathrm{F}(1.1039)$} & \multirow[b]{2}{*}{ Partial Eta } \\
\hline & M & SD & M & SD & & & M & SD & M & SD & & \\
\hline $\begin{array}{l}\text { Cyber } \\
\text { bullying }\end{array}$ & .23 & .42 & .12 & .27 & $8.39^{* * *}$ & .019 & .07 & .28 & .11 & .48 & $3.69^{*}$ & .004 \\
\hline Social support & 5.88 & 1.41 & 5.89 & 1.33 & 1.44 & 0 & 5.72 & 1.51 & 6.03 & 1.28 & $25.91^{* *}$ & .026 \\
\hline Autognosis & 3.61 & .74 & 3.8 & .66 & $3.8^{*}$ & .013 & 3.74 & .70 & 3.62 & .79 & .13 & 0 \\
\hline Happiness & 4.5 & 1.61 & 4.89 & 1.35 & $12.9^{* *}$ & .015 & 4.81 & 1.42 & 4.78 & 1.39 & .07 & .001 \\
\hline $\begin{array}{l}\text { Body } \\
\text { perception }\end{array}$ & 2.3 & .76 & 2.33 & .72 & 1.85 & 0 & 2.49 & .73 & 2.19 & .81 & $26.98^{* *}$ & .030 \\
\hline
\end{tabular}

$* p<0.05$

$* * p<0.01$

Table 3 indicates the mean, standard deviation and score between student group (with and without learning disabilities) and gender after one-way analysis of variance. The research results show that the students with learning disabilities may be cyber victims compared with those without learning disabilities. They have lower autognosis and happiness in real life and show the inferiority complex. These characters cause easy bullying during the communication with peers. In the meantime, such harmful behaviors are also easily reflected in another form in the Internet. In gender comparison, female college students have lower body perception, and are more easy to become the cyber victim compared with male students. However, in the social support, their proportion is higher than that of male students. The sex factors of female students are easy to be attacked, and meanwhile female students would rather confide to others compared with male students so as to accept more social support.

\section{CONCLUSION BASED ON DATA ANALYSIS}

The cyber bullying experience of college students with or without learning disabilities have been surveyed in the research, and the relationships among measurement indicators cyber bullying and social support, autognosis, subjective happiness and body perception have been discussed. Based on the data analysis, four main conclusions have been obtained: first, the proportion of students with learning disabilities becoming cyber victims is higher compared with those without learning disabilities (25.38\% VS 9.14\%). Second, the students with learning disabilities have obviously lower autognosis and happiness compared with those without learning disabilities. Female students have more cyber bullying, higher social support and lower body perception compared with male students. Third, the cyber bullying is significantly correlated to the social support, social and emotional autognosis, happiness, gender and student group for the whole sample. Fourth, the gender difference reveals that female students are easier to become cyber victims than male students but have higher social support as well.

\section{SPECIFIC MEASURES TO PREVENT COLLEGE CYBER BULLYING}

The college guidance department can assist in the student psychological counseling and individual counseling in and out of the colleges. Through such counseling and assistance, the students, faculty and staff can be trained to prevent the cyber harm, and the individuals with such experience can be provided with psychological support and guided for methods. The research results show that it is necessary to implement the coping strategies to support the students with learning disabilities in different fields, so as to strengthen their autognosis and improve their happiness, and assist them in protecting themselves from becoming cyber victims $^{[10]}$.

The significance of disability plays a role in the bullying in university campus, which shows that particular attention shall be paid to the accommodation of students by the student psychological counseling department and the dormitory management department of colleges. More efforts shall be made in the process to safeguard the privacy. 
In policy, the colleges shall strengthen the education in cyber-security, and the students should understand that the cyber bullying is unacceptable and there will be consequences like face-to-face attack. Besides, the competent administrative department for education can also provide a network to explain the risk of cyber bullying, and release the guidelines to reduce the risk of cyber bullying.

For the future research, it is required to build a specific model to identify the influence by experience and individual psychology, including the adults with various disabilities and the students with different genders and the life backgrounds in various regions. Besides, the intervening measures and strategic planning shall be taken in the future research to inspect the effectiveness to reduce the cyber bullying and increase students' self-confidence, particularly for the high risk group of cyber bullying.

\section{REFERENCES}

[1] Feng Jianjun. (2018) Cyber Bullying and Its Preventive Education[J]. Research in Educational Development, Volume 12: 49-54.

[2] Ming Leqi. (2018) Research on Cyber Bullying Behaviors of Teenagers[J]. Journal of Jiangsu Police Institute, Volume 4: 42-48.

[3] Bao Hongxia. (2018) Construction of "Combination Blow" as a Countermeasure for "Cyber Bullying" in Institutions of Higher Education [J]. Journal of Higher Education, Journal 5, Volume 7: 130-131.
[4] Zhu Yuhong and Chen Qun. (2014) Review and Latest Progress of Cyber Bullying Research Abroad [J]. China Youth Study, Volume 11: 81-85.

[5] Song Shuxue and Fan Fumin. (2006) Network Subjective Education: a New Topic of Moral Education of College Students in Network Age [J]. Journal of Ideological \& Theoretical Education, Volume 5: 52.

[6] Li Yunxin. (2018) Research Review of Characteristics of Cyber Bullies [J]. Education Science Forum, Journal 3, Volume 421: 75-77.

[7] Zhu Yuhong, Chen Qun and Zhou Huazhen. (2014) Review and Latest Progress of Cyber Bullying Research Abroad. China Youth Study. Volume 11, 80-85.

[8]Cialdini,R. B. , \& Goldstein, N. J . (2004) Social influence: Compliance and conformity [J]. Annual Review of Psychology, Journal 3, Volume 55: 591-601.

[9] Crockett, M.J. (2013) Models of morality [J]. Trends in Cognitive Sciences, Journal 15, Volume 17: 363-366.

[10] Lindström, B., Jangard, S.Selbing, I., \& Olsson, A. (2018) The role of a "common is moral" heuristic in the stability and change of moral norms [J]. Journal of Experimental Psychology General, Volume 147: 228230. 